\title{
9 De Barral a Herralde. Enlace
}

Una escena extraída de la ya mencionada Historia personal del "boom", de José Donoso, condensa de modo iluminador la trama que interesa en este capítulo. Así recuerda el escritor chileno una velada en 1970 en la casa de Luis Goytisolo en Barcelona:

\begin{abstract}
Cortázar, aderezado con su flamante barba de matices rojizos, bailó algo muy movido con su esposa Ugné; los Vargas Llosa, ante los invitados que les hicieron rueda, bailaron un valcesito peruano, y luego, a la misma rueda que los premió con aplausos, entraron los García Márquez para bailar un merengue tropical. Mientras tanto, nuestro agente literario, Carmen Balcells, reclinada sobre los pulposos cojines de un diván, se relamía revolviendo los ingredientes de este sabroso guiso literario, alimentado, con la ayuda de Fernando Tola, Jorge Herralde y Sergio Pitol, a los hambrientos peces fantásticos que en sus peceras iluminadas decoraban los muros de la habitación: Carmen Balcells parecía tener en sus manos las cuerdas que nos hacían bailar a todos como a marionetas, y nos contemplaba, quizás con admiración, quizás con hambre, quizás con una mezcla de ambas cosas, como contemplaba a los peces danzando en sus peceras. (115)
\end{abstract}

Este capítulo está dedicado a la editorial Anagrama, como uno de los grandes agentes productores de literatura (latinoamericana) mundial en lo que va, progresivamente, de los años 80 en adelante. Del escenario que monta Donoso, interesa la continuidad que conduce del proyecto de Carlos Barral al de Jorge Herralde. Al margen de que la primera edición de Historia personal del boom apareció en Anagrama y puede ser considerada tanto un epílogo a la historia del boom como la inauguración de un nuevo horizonte, propongo leer este encuentro o ritual de interacción, en el sentido que le asigna Randall Collins, como un momento donde comienza a articularse un relevo decisivo -y hasta el momento poco atendido por la investigación- para la suerte de la literatura latinoamericana (mundial). Si los escritores que aparecen bailando en el primer párrafo constituyen, con Carlos Fuentes, el núcleo estelar del boom de los años 60 y Carmen Balcells la principal gestora de la economía material, y en parte también simbólica, del boom, Jorge Herralde y Sergio Pitol encarnan una asociación productiva que va a tomar la posta del boom y poner en movimiento la maquinaria que va a mostrar síntomas de madurez recién a fines de los años 90 con el lanzamiento al mercado internacional de Los detectives salvajes (1998). Mientras que Jorge Herralde va a asumir los riesgos de inversión y la coordinación general del programa editorial de Anagrama, cada vez más atento a literaturas promovidas como latinoamericanas, Sergio Pitol, en tanto primer escritor de origen latinoamericano reconocido simbólicamente con el Premio Herralde de Novela (1984), va a corresponderse con el carácter emblemático que en los años 60

Ә Open Access. (c) 2019 Jorge J. Locane, published by De Gruyter. (c) BY-NC-ND This work is licensed under the Creative Commons Attribution-NonCommercial-NoDerivatives 4.0 License.

https://doi.org/10.1515/9783110622096-009 
adquirió Mario Vargas Llosa para el proyecto de Barral. La continuidad que sugiero conduce, por lo tanto, de Barral / Vargas Llosa, en los años 60, a Herralde / Pitol, en los 80. ${ }^{1}$ En ambos casos, no obstante, con un mismo lugar geográfico de enunciación: Barcelona.

El hilo que hilvana la primera dupla con la segunda no es únicamente del orden posicional, es decir que no solo se refiere al necesario relevo en el campo literario internacional que va a tener lugar después del debilitamiento y reconfiguración del programa de la editorial Seix Barral (1955-1970), la desaparición del Premio Biblioteca Breve en 1972 y la muerte de Carlos Barral en 1989, sino que también pertenece a la esfera de lo procedimental. De Barral, Herralde hereda un conocimiento y un repertorio de estrategias que, en la estela del primero, le van a permitir conciliar exitosamente dos elementos por regla general reñidos: literatura considerada por lo menos aceptable por la zona más especializada del campo y negocios. Además de un sólido diseño para el perfil de editor definido por un celoso seguimiento del catálogo que en ambos casos se va a distinguir por asignarle, desde España, un lugar prominente a la literatura de corte latinoamericano en el marco mayor de la literatura mundial.

Enlace, la distribuidora que en los años 70 reunió a Barral, Herralde y otros editores, puede ser considerada la institución formal donde va a tener lugar la articulación de los proyectos y el legado de conocimientos. Al respecto, Sergio Vila-Sanjuán anota: "El núcleo duro editorial de la gauche divine está concentrado hasta 1975 en la distribuidora Enlace: el propio Carlos Barral, su fundador e impulsor junto con Anagrama, Lumen, Tusquets -cuyos respectivos directores Jorge Herralde, Esther Tusquets y Beatriz de Moura admiran positivamente a Barral y lo consideran un modelo y maestro- encarnan al cien por cien el espíritu del grupo" (99). Así, la experiencia compartida en Enlace va a operar como instancia de formación para los editores de una generación menor en relación con Barral, ya que para el momento de la fundación, en 1970, Barral ya se podía atribuir una trayectoria de éxito en lo que refiere a modificación de hábitos de lectura, configuración de un catálogo, proyección internacional, aprobación académica y rentabilidad económica. Que los respectivos emprendimientos encontraran un lugar de confluencia concreta en una distribuidora es un dato a considerar si se recuerda la importancia que va a tener la cobertura territorial para proyectos, por lo pronto, de corte panhispánico, pero también con miras a una posterior puesta en circulación en otros espacios lingüísticos. Voy a retomar el punto más adelante.

1 Para un análisis de Pitol como "literatura mexicana mundial”, véase Sánchez Prado Strategic. 
El mismo Jorge Herralde reconoce en Barral "un reverenciado hermano mayor" ("Introducción..." 19) y Andreu Jaume, en la introducción a la edición más reciente de las Memorias de Barral, lo constata del siguiente modo:

\begin{abstract}
Más que editor, Barral fue lo que los anglosajones llaman un publisher, alguien que no se ocupa tanto del detalle de los libros cuanto de la general vertebración e implantación de su catálogo, defendiendo la razón del criterio frente a tiranías varias, entre ellas la del mercado. Como Publisher, Barral creó para España, casi desde la nada, una tradición, fundando un modelo que luego haría más el camino de editores como Esther Tusquets al frente de Lumen o el de Jorge Herralde en Anagrama y que ha inspirado también el trabajo de los editores nacidos con la democracia. El legado más sólido de su trabajo editorial estriba en el coraje, en el apasionamiento a la hora de defender un gusto, en la valentía por propiciar el reconocimiento de la "literatura ajena", con una determinación y una intransigencia que ya empezamos a echar de menos. (24)
\end{abstract}

En efecto, uno de los grandes logros de Carlos Barral consistió en sacar la edición española del repliegue y achatamiento a los que la había conducido la dictadura de Francisco Franco y establecer una red de acción con una importante ramificación internacional. Pero, si bien se puede sostener que esta fue una operación sui generis para la España del régimen dictatorial, difícilmente pueda argumentarse que su modelo se funda "en la nada" absoluta. Como ha observado Sara Carini, un referente de peso para Carlos Barral lo va a constituir el editor italiano Giulio Einaudi quien ya había establecido coordenadas fiables para una gestión editorial de miras amplias en el contexto represivo y siempre limitante de la Italia fascista. Según registra Barral en sus Memorias, su encuentro con Giulio Einaudi fue un episodio decisivo para su futuro desarrollo como editor y, por lo tanto, también para la evolución de la literatura latinoamericana que empezaría a perfilarse como mundial. Giulio Einaudi, afirma Barral, "Hizo crecer de pronto al personaje que yo venía luchando por mantener fuera de la persona. Un personaje absorbente y peligroso que se ha ido poniendo, hasta ahora, casi todas mis camisas" (560). Ese personaje -hasta el momento Barral prefería identificarse como "poeta"- va a ser el editor fríamente calculador capaz de conjugar de manera exitosa literatura y rentabilidad económica. Además de legarle un repertorio de estrategias profesionales, va a ser su vacilación frente a las implicancias contenidas en tal ensamblaje lo que Einaudi va a lograr despejar del horizonte ideológico de Barral. Al comentar una larga serie de conversaciones con el editor italiano en Calafell, sostiene que incluso en 1959 él aún seguía indeciso en lo que respecta a asumir plenamente tal personaje, e informa sobre las razones:

Yo no estaba seguro de la transparencia de nuestra función profesional, de la justificación de un poder de notables alcances en el terreno de la fundación de las famas, de la suerte 
de las carreras profesionales y, sobre todo, de la sedimentación de valores tantas veces teñidos de arbitrariedad o de orígenes casi aleatorios. Porque, a partir de un determinado caudal de publicación, no era ni siquiera una función personal, dependía en gran medida de la coincidencia de unos ciertos colaboradores y de los condicionantes empresariales. Estábamos continuamente al borde de jugar sucio, defendiendo libros que tal vez ni habíamos leído o que habíamos más o menos leído en circunstancias despersonalizantes y engañadoras, bajo una atmósfera de pequeñas presiones y en un contexto de prejuicios. (558)

Lo cierto es que tras las conversaciones con Giulio Einaudi, Barral abandona sus reservas respecto a la función del editor y, rápidamente, se convierte en uno de los grandes protagonistas de la edición española con perspectiva mundial: "La idea del premio, la conversación con Einaudi, el acuerdo de Víctor Seix, la habilidad de Salinas, me lanzaron a una para mí vertiginosa y objetivamente desproporcionada actividad de negociador y al mismo tiempo de editor de grandes vuelos que me introdujo, de golpe, en los intestinos de la gran edición europea” (560). En relación con esto último, con la superación del horizonte nacional emprendida por Barral, la operación llevada a cabo en Formentor, Mallorca, desde fines de los años 50 merece cierto detenimiento.

Los premios Formentor y los encuentros, coloquios y charlas en el hotel del mismo nombre poseen, al igual que el Premio Biblioteca Breve -otra operación clave en lo que atañe a la literatura latinoamericana mundial-dos momentos. De 1959 a 1968, el período temprano y por supuesto decisivo para la articulación del boom, el programa general va a estar conducido por Carlos Barral y Giulio Einaudi. Desde la revitalización en 2007 hasta el presente, en contraste, va a correr por cuenta de la fundación Santillana. El primer coloquio internacional estuvo dedicado a la novela. El segundo, en 1960, es de capital importancia para el diseño de la estrategia editorial internacionalista que va a caracterizar desde entonces a Seix Barral y, más tarde, a Anagrama. Los temas en cuestión fueron "El editor y el novelista” y "El editor y el público”. Mario Santana sostiene que

Con la participación de representantes de seis destacadas editoriales del panorama mundial -Gallimard (Francia), Rowohlt (Alemania), Einaudi (Italia), Weidenfeld \& Nicholson (Reino Unido), Grove Press (Estados Unidos) y Seix Barral- el Segundo Coloquio Internacional de Novela fue no sólo una oportunidad para que esos editores culturales discutieran su función en la conformación del comercio y las tendencias literarias, sino que sirvió asimismo para sentar las bases de una operación cultural más ambiciosa. (289)

El proyecto de coordinar la publicación internacional de literatura de ficción en función de un beneficio corporativo contó desde entonces con un núcleo de gestión formal autodenominado Grupo Formentor, en el cual, junto a las casas 
editoriales originales llegaron a confluir un total de catorce, incluida, por ejemplo, Choukorow-Sha de Japón. En sus Memorias, Carlos Barral recuerda precisamente este Segundo Coloquio de la siguiente manera: "Estábamos allí, los editores y sus agentes, para llegar a un acuerdo, para institucionalizar nuestra colaboración y fundar un instrumento útil a la circulación internacional de literatura que favoreciera, además, de algún modo, nuestros intereses” (571). Queda explícito, por lo tanto, el carácter programático a partir del cual se van a desplegar las futuras estrategias de publicación y traducción de la coalición. "La circulación internacional de literatura” ideada en Formentor, de la que sin duda va a usufructuar particularmente bien el boom latinoamericano, va a catalizar en la progresiva conformación de catálogos representativos de una emergente literatura mundial favorable "además" a los intereses de la industria editorial metropolitana todavía con sesgo culturalista. El procedimiento consistiría en el lanzamiento simultáneo, en original y traducción, de novedades en los mercados más desarrollados de Occidente con el fin de economizar los procesos de preselección y de que el éxito en uno pudiera funcionar como aval en otros. El carácter corporativo y la confluencia de intereses, además, actuarían como respaldo simbólico y malla de contención frente a potenciales riesgos.

Una mención especial merecen los dos premios que el Grupo instituyó y comenzó a entregar desde 1961: el Prix Formentor, “que serviría para promocionar novelas que ya estaban en manos de alguno de los editores implicados y cuyos autores se beneficiarían de la traducción y publicación inmediata de su obra en catorce países” (Santana 291) y el Prix International que, en 1961, "representó el primer reconocimiento internacional de [Borges] [...], quien posteriormente recordaría que fue gracias a ese premio que sus libros empezaron a venderse en todo el mundo" (Santana 291). La lista completa, del primer y segundo período, comprende los siguientes nombres:

\section{Prix Formentor}

1961 - Juan García Hortelano, Tormenta de verano

1962 - Dacia Maraini, L'età del malessere

1963 - Jorge Semprún, Le grand voyage

1964 - Gisela Elsner, Die Riesenzwerge

1965 - Stephen Schneck, The Nightclerk

1966 - -

1967 - vacante

Segunda etapa: Premio Formentor de las Letras

2011 - Carlos Fuentes

2012 - Juan Goytisolo 


$$
\begin{aligned}
& 2013 \text { - Javier Marías } \\
& 2014 \text { - Enrique Vila-Matas } \\
& 2015 \text { - Ricardo Piglia } \\
& 2016 \text { - Roberto Calasso } \\
& 2017 \text { - Alberto Manguel }
\end{aligned}
$$

Prix International

$$
\begin{aligned}
& 1961 \text { - Jorge Luis Borges, Ficciones y Samuel Beckett, Trilogy } \\
& 1962 \text { - Uwe Johnson, Mutmassungen über Jakob } \\
& 1963 \text { - Carlo Emilio Gadda, La cognizione del dolore } \\
& 1964 \text { - Nathalie Sarraute, Les fruits d'or } \\
& 1965 \text { - Saul Bellow, Herzog } \\
& 1966 \text { - - } \\
& 1967 \text { - Witold Gombrowicz, Kosmos }
\end{aligned}
$$

De estos dos premios, que van a constituir la columna vertebral del proyecto del Grupo Formentor, y que en el programa más específico de Carlos Barral, se van a articular estratégicamente con el Biblioteca Breve, me interesa destacar dos aspectos que lo conectan con el posterior proyecto de Jorge Herralde. En primer lugar, como se extrae de la lista, la etapa que se inaugura en el 2011 va a caracterizarse por una fuerte presencia de escritores emblemáticos de Anagrama o, dicho en otros términos, que el organismo institucional Formentor, refundado en 2007, puede considerarse desde entonces, al menos en cierto sentido, un agente promotor no ya en la órbita de Seix Barral sino de Anagrama. El segundo, y acaso más importante, es que en la vocación internacionalista que nutre el armado temprano de Formentor, Herralde va a encontrar una clave fundamental para su propio emprendimiento. Un tipo de premisa procedimental que se va a expresar en el tejido de alianzas estratégicas con otros editores europeos y en la puesta en marcha de políticas editoriales corporativas favorables a reducir riesgos en la producción de literatura mundial. En 1976, por ejemplo, como parte de un relevo generacional, va a tener lugar una suerte de intento de actualización y refundación del Prix Formentor para reemplazar al original que había sido suspendido en $1967^{2}$ : el efímero Premio Internacional de los Siete Editores. Jorge Herralde recuerda que

2 Cabe destacar que la referencia, y el que se va a intentar restituir, es el Prix Formentor y no el Prix International. Mientras que el segundo fue concebido como un reconocimiento a la trayectoria, sin beneficios económicos para los editores asociados; el primero habría tenido desde el primer momento un carácter decididamente comercial, ya que se trataba de una distinción a un texto inédito que a continuación sería insertado, mediante el pago de anticipos -y este sería el 
Por aquel entonces, en 1976, varios editores europeos independientes -más o menos izquierdistas y más o menos arruinados- decidieron otorgar un premio anual de literatura a un manuscrito inédito y publicado simultáneamente en los países de cada editor. Entre los promotores estaban Klaus Wagenbach, Inge Feltrinelli, Christian Bourgois y John Calder, que tuvieron la gentileza de cooptarme como editor español. Las otras editoriales participantes fueron Van Gennep y Dom Quixote.

El premio tuvo una vida aún más efímera de lo habitual en tales proyectos, ya que sólo se concedió un año, al libro Cien poemas apátridas del austríaco Erich Fried, que había sido propuesto por Klaus Wagenbach. Luego, a los tradicionales problemas de copyright y de expectativas distintas de los editores, habituales en tan voluntaristas certámenes, se unió la crisis económica que afectó a casi todos nosotros. Guardo muy grato recuerdo de aquellos encuentros, que iniciaron o consolidaron mi amistad con los editores confabulados. ("Introducción..." 20)

Anagrama comienza a operar en 1969 como una editorial especializada en pensamiento y ensayo político, comprometida, decididamente, con el plan de emancipación de la dictadura franquista. A las tres primeras colecciones, "Argumentos", "Documentos" y "Textos" se van a sumar "Cinemateca Anagrama”, "Biblioteca de antropología”, “Ibérica”, "Debates” y "Elementos críticos”. Entre estas colecciones, se van a distribuir títulos como Nietzsche y la filosofía, de Gilles Deleuze, Cartas sobre las ciencias de la naturaleza y las matemáticas, de Karl Marx y Friedrich Engels, Los tupamaros, de Antonio Mercader y Jorge de Vera, Pequeña antología, de Ulrike Meinhof, La crisis de la socialdemocracia, de Rosa Luxemburg, La revolución española, de Joaquín Maurín y Lógica de la libertad. Por un marxismo libertario, de Enrique Gil Calvo.

\footnotetext{
"premio"-, en el mercado internacional. El grupo Formentor, liderado por Giulio Einaudi, llegó a la decisión de instaurar los dos premios después de los primeros encuentros en 1959 en el hotel. Carlos Barral registró en sus Memorias las razones que argumentaban en favor de un premio o del otro: "leídos y juzgados como propuestas de publicación por todas las editoriales participantes, los como máximo dos o tres candidatos de cada editor, que totalizarían a lo sumo una docena de libros ampliamente informados y discutidos en cada sede, serían objeto de un debate comparativo, en Formentor, por ejemplo, por los titulares o especialistas de las marcas, que otorgarían un premio constituido por la suma de anticipos de derechos de autor, y el compromiso de publicar en una fecha determinada, al año, con ocasión de la nueva reunión, sería una buena idea, la mismas en todas partes. No, no era convincente. Si de lo que se trataba era de acelerar la comunicación entre literaturas relativamente estancas o tan solo comunicadas por la resonancia del éxito, era más lógico pensar en un premio de reconocimiento, una especie de Nobel para escritores no todavía decrépitos o disecables para la clase académica internacional, de autores que, si prestigiosos en reducidos círculos de su propio país, eran desconocidos o solo materia de crítica especializada más allá de las propias fronteras. Un premio en sentido propio. Nada de anticipos" (556-557). Carlos Barral había tomado posición por el primer modelo, el que decantaría en el Prix Formentor, sobre lo que consigna que "Defendía un mecanismo comercial con argumentos supuestamente culturales" (558).
} 
Recién en 1977, ya muerto Franco e inaugurada la transición, la literatura de ficción va a hacerse presente en una colección compartida con el nuevo periodismo, “Contraseñas”. En esta colección van a tener su lugar dos nombres que con el tiempo devendrían emblemáticos de la casa: Charles Bukowski y Copi. Pero habrá que esperar hasta comienzos de los años 80 para que aparezcan las colecciones que hoy valen por las más representativas de la editorial: en 1981 hace su debut "Panorama de narrativas", la célebre colección amarilla "dedicada a la literatura extranjera" ("Introducción...” 20), y en 1983, "Narrativas hispánicas” que, al contrario de lo que se podría esperar, está dedicada a la narrativa española y, progresivamente aunque ya desde temprano, a la hispanoamericana, es decir, también a literaturas extranjeras, pero escritas en castellano. Me interesa subrayar la codificación del binomio "extranjera"/"nacional" como sinónimo de “extranjera”/“hispánica” para dejar constancia de que el espíritu panhispanista que va a caracterizar a la editorial desde fines de los años 90 ya estaba presente como germen en el momento de fundación de estas colecciones. La marca plural de "Narrativas hispánicas" debe entenderse, por lo tanto, como un esfuerzo por (re)inscribir las diferentes declinaciones nacionales de la narrativa en castellano bajo un signo mayor hispánico, con su "meridiano" no ya en Madrid, como quería Guillermo de Torre por los años 20, sino en Barcelona, como bien lo había determinado -y dejado como legado- la política del boom en los años 60 (cfr. Espósito).

Con el tiempo estas dos colecciones se van a consolidar como la columna vertebral del proyecto de Jorge Herralde: van a mantenerse hasta la actualidad y ver desaparecer colecciones menos aceptadas o favorecidas, además de que van a concentrar el importante capital simbólico que representan los nombres de autor más ligados al programa editorial y ahora característicos de él. Los primeros nombres de "Panorama de narrativas" van a ser, entre otros, Thomas Bernhard, Joseph Roth y la fundamental Patricia Highsmith, a quienes ya en 1982 se van a agregar John Kennedy Toole, Ian McEwan y el premio Nobel (1969) Samuel Beckett. "La colección" -comenta Herralde- "se consolidó con el éxito arrollador e inesperado de La conjura de los necios de John Kennedy Toole y de los libros de Patricia Highsmith protagonizados por Tom Ripley, con A pleno sol por delante" ("Introducción...” 20). A estos dos pilares, a su vez, se van a ir añadiendo otras figuras capitales de la narrativa occidental del siglo XX. En 1986 se incorpora Vladimir Nabokov con Habla, memoria y Lolita. Los Relatos, de William Faulkner, van a aparecer en 1990 y Mientras agonizo en el 2000. Raymond Carver va a estar presente desde 1986 con Catedral y William Burroughs desde 1989 con El almuerzo desnudo. Truman Capote, Roberto Calasso, Claudio Magris, Norman Mailer, Jean Echenoz, Martin Amis, Kenzaburo Oé y el flamante Premio Nobel Kazuo Ishiguro también van a ir incorporándose 
progresivamente por esos años. ${ }^{3}$ Paul Auster, otro de los nombres capitales de la colección amarilla, va a ingresar en 1990 con El palacio de la luna para llegar a sumar, al 2013, con Informe del interior la cantidad de treinta y dos títulos mientras que, para el mismo año, de Charles Bukowski se contaban, entre la colección “Contraseñas” y "Compactos”, dieciocho. Destaco la marcada presencia de estos dos escritores en la colección por la importancia que William Marling les asigna en Gatekeepers, su reciente estudio sobre la producción de literatura mundial. A Bukowski le dedica el capítulo dos. Sobre el primero, a quien está dedicado el capítulo cuatro, Marling escribe que, a mediados de los 80, "Auster became the most important US writer of World Literature in France” (10).

En paralelo a "Panorama de narrativas" y como una prueba de la capacidad de Herralde para observar y colocarse en la confluencia de los tráficos de literatura mundial, va a ir tomando forma "Narrativa hispánicas”. Comenta Herralde que la "bonanza [producida por el temprano éxito comercial de Highsmith y Toole] permitió la puesta en marcha en 1983 de una experiencia apasionante: la colección 'Narrativas hispánicas"” (“Introducción...” 20). Los primeros años de esta colección van a evidenciar un énfasis en la emergente narrativa española de la transición. La inauguración de la serie va a estar representada por El héroe de las mansardas de Mansard, de Álvaro Pombo, a quien al año siguiente se van a sumar, entre otros, el para entonces ya consagrado Luis Goytisolo, con Estela de fuego que se aleja, Enrique Vila-Matas, con Impostura, y Félix de Azúa, con Mansura. En los próximos años, van a incorporarse nombres con no menos valor simbólico como Javier Tomeo, Javier Marías, Paloma Días-Mas y, en 1988, Rafael Chirbes con Mimoun.

Esta colección, no obstante, no puede ser pensada de manera acabada sin considerar el Premio Herralde de Novela. ${ }^{4}$ Álvaro Pombo fue el primero en recibirlo en 1983 y también quien inaugura el catálogo hispánico. El Premio Biblioteca Breve, conviene recordar, se había entregado desde 1958 hasta 1972 en doce ocasiones bajo un espíritu de claro carácter panhispanista. Junto con catapultar el fenómeno del boom, sirvió como plataforma de difusión para escritores propiamente españoles. La lista de títulos favorecidos con el premio durante aquellos años arroja el siguiente resultado:

3 A Kazuo Ishiguro, un nombre también central del catálogo de Anagrama -en el que está presente desde 1988 con Pálida luz en las colinas-, Rebecca Walkowitz le dedicó, antes de que recibiera el Premio Nobel en 2017, el capítulo II de su estudio Born Translated, donde señala que sus novelas fueron traducidas a más de 40 lenguas y que "More than any other writer of anglophone literary fiction, Ishiguro has reflected on and largely affirmed translatability" (94). 4 Al respecto de la función e importancia del premio, puede consultarse Locane "El Premio...". 


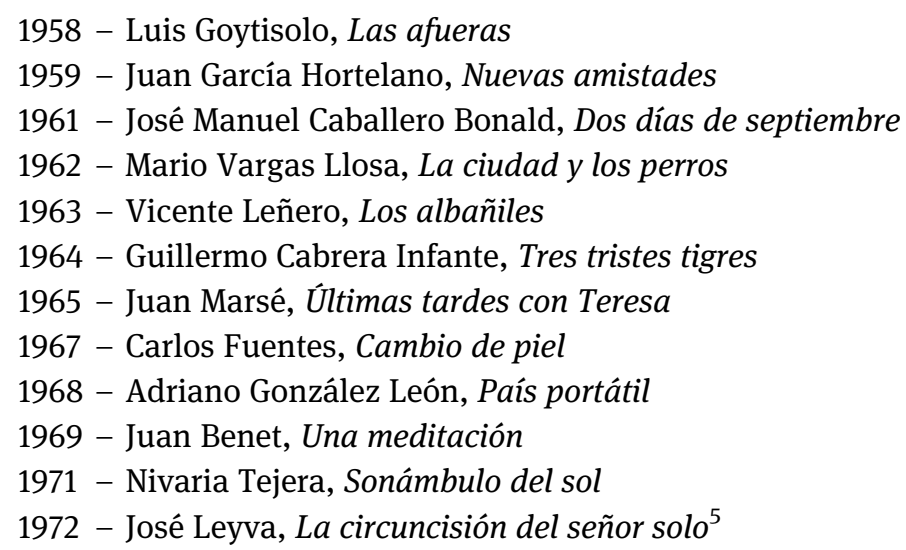

Once años después, el Premio Herralde de Novela va a ocupar el lugar que había quedado vacante bajo un mismo diseño conceptual y una misma idiosincrasia. Luis Goytisolo, el primero reconocido con el Biblioteca Breve va a incorporarse, progresivamente, al catálogo de Anagrama. Si bien ya estaba presente desde 1970 en la "Serie informal", va a ser con "Narrativas Hispánicas" que va a consolidar su presencia, hasta llegar a la monumental Antagonía (2012) que ya había sido publicada parcialmente en Seix Barral y que en Anagrama va a ocupar el emblemático número 500 en la lista de la colección.

Como ya he sugerido anteriormente, a Mario Vargas Llosa en Seix Barral va a corresponderle Sergio Pitol en Anagrama. Con el reconocimiento en 1984 y la posterior publicación de El desfile del amor -de ahí en más todo título favorecido con el Premio de Novela va a aparecer publicado en "Narrativas hispánicas"-, la política editorial de Anagrama va a delimitar el corpus de las narrativas hispánicas como comprendidas por la española y, potencialmente, la de todos los demás países de habla hispana.

A esta demarcación del territorio, va a seguir una fase en la que la literatura de raigambre latinoamericana no va a recibir mayor atención; mucho menos la producida directamente en el subcontinente. En 1984, cuando la colección incorpora en total catorce títulos, junto con el tercero de Sergio Pitol, va a aparecer Vudú urbano, de Edgardo Cozarinsky. En 1986 se suman otros doce títulos, entre ellos, uno más de Pitol, El tañido de una flauta, y De Pe a Pa (o de Pekín a París), de Luisa Futoransky. En 1987, los títulos nuevos van a ser en total dieciséis, mientras que los de escritores de origen latinoamericano solo dos: $E l$

5 Además del libro de Pohl, sobre el Premio Biblioteca Breve puede consultarse la tesis doctoral de Judith Illerhaus. Véase también Dravasa. 
cielo de Sotero, de Alejandro Rossi, y, en un solo volumen, Las ratas \& Sombras suele vestir, de José Bianco. Este promedio de uno o dos títulos de escritores latinoamericanos, residentes por lo general en Europa y vinculados con anterioridad a la editorial, se va a mantener hasta 1997, año que debe ser considerado bisagra en la política panhispanista de Anagrama. Desde ese momento la presencia de escritores latinoamericanos, residentes en Europa y ahora también cada vez más en América Latina, se va a acrecentar a un ritmo significativo. El Premio Herralde de Novela de ese año lo recibe -lo que no sucedía desde el otorgado a Pitol en 1984- el peruano Jaime Bayly con La noche es virgen, mientras que, de los veintiséis títulos que va a incorporar la colección, nueve son atribuidos a latinoamericanos. De este modo el porcentaje anual correspondiente a literaturas latinoamericanas dentro del corpus mayor de las "narrativas hispánicas” pasa a ser del 35\%, un número que se va a mantener más o menos estable hasta la actualidad y que sin duda le debe mucho a la gran repercusión internacional que un año más tarde generó el reconocimiento de Los detectives salvajes con el Premio Herralde de Novela, su posterior publicación y el enorme éxito tanto de ventas como de crítica.

Esta evolución que va del énfasis en el ensayo y el pensamiento en los años 70 , para pasar a la narrativa en general en los 80 y más tarde, hacia fines de los 90, incorporar programáticamente las literaturas latinoamericanas como parte un ideario panhispanista merece algunas reflexiones. Después del apogeo del boom, motorizado y capitalizado en primer término por Seix Barral, y su posterior decaimiento o pasaje a una modalidad recursiva, la producción renovadora de literatura latinoamericana mundial había quedado como una tarea vacante. Hacia mediados de los 90, en el marco de la nueva configuración histórica signada simbólicamente por la Caída del Muro de Berlín y, para el mundo hispanoamericano, por el quinto centenario de la llegada de los españoles a América, se observa un proceso de reactualización de la agenda de la literatura latinoamericana mundial encabezado por las editoriales españolas de mayor envergadura: en 1993, Alfaguara, como parte del grupo Prisa desde 1980, lanza el programa Alfaguara Global y en 1998 revitaliza el Premio Alfaguara de Novela ${ }^{6}$ que se va a repartir entre Eliseo Alberto de Cuba y Sergio Ramírez de Nicaragua;

6 Así aparece caracterizado actualmente el programa en el sitio de la editorial: "El proyecto Alfaguara Global, en el que toma cuerpo esta actitud de Alfaguara, se inicia en 1993 con la publicación de Cuando ya no importe, de Juan Carlos Onetti, uno de los autores emblemáticos de la literatura latinoamericana de nuestro siglo. Esta edición, fruto del esfuerzo común de todos los editores de Alfaguara a uno y otro lado del Atlántico, ha señalado el camino a seguir. Desde entonces se han venido sucediendo los lanzamientos de escritores españoles y latinoamericanos, tanto del boom como de las nuevas generaciones, en un permanente camino de ida y vuelta 
en 1999 Seix Barral, bajo el tinglado corporativo de Planeta, relanza el Premio Biblioteca Breve y se lo otorga a Jorge Volpi; mientras que Anagrama, al mismo tiempo que aumenta la representación de escritores latinoamericanos en su catálogo y los distingue con sus premios, refuerza su presencia en América Latina mediante una política de coediciones y el fortalecimiento de su red de distribución.

Se deduce, por lo tanto, que esta reorientación por parte de Anagrama no es ajena a coordenadas históricas tendientes a refundar los lazos coloniales entre España y las (ex)dependencias al otro lado del Atlántico. El 35\% comentado arriba va a alcanzar un pico de $50 \%$ a mediados de los años 00 como resultado de una política editorial conscientemente guiada por las tendencias de época. ${ }^{7}$ Como han observado varios investigadores (Morgan, Valle, Espósito, Pohl "Estrategias...”), la restauración neocolonial se va a llevar a cabo desde un frente económico encarnado por empresas como Telefónica, Repsol y el Banco Santander, y desde el simbólico, donde tanto organismos públicos, como el Instituto Cervantes y la Real Academia Española, como privados, las corporaciones de la industria cultural, van a hacer su parte al comenzar a operar en función de un sentido de pertenencia fundado en la lengua y una identidad panhispánica. En lo que respecta específicamente a la edición y puesta en circulación de libros, Burkhard Pohl argumenta que, para esta época,

También la edición española empezó nuevamente a mirar hacia América económica y literariamente. Coincidió este interés con diferentes procesos en el mercado literario: la exploración de nuevas redes de distribución, la concentración vertical y horizontal de empresas editoriales, el creciente papel de los agentes literarios, la nueva presencia de escritores latinoamericanos en los centros de edición en español. (“Estrategias...” 15) ${ }^{8}$

de América a España, de España a América, que cada vez dota de mayor sentido la vocación global de Alfaguara.

El Premio Alfaguara de Novela, que se viene convocando desde 1998, también apunta claramente en esta dirección. En él se vuelcan todas las sedes de Alfaguara para editar, distribuir y promocionar la novela ganadora por todo el ámbito del español, consiguiendo así llegar a cuatrocientos millones de lectores potenciales”. Un estudio sobre el proyecto se encuentra en Pohl “¿Un nuevo boom?”.

$7 \mathrm{Al}$ respecto Jorge Herralde comenta que "Así, en Anagrama [...] la ocupación del catálogo ha variado sensiblemente: tanto en 2004 como en 2005, los veinte títulos anuales se han repartido mitad y mitad entre autores españoles y latinoamericanos, algo absolutamente impensable hace sólo cuatro y cinco años” (“El editor independiente...” 237-238).

8 En una línea similar, siguiendo argumentos de Ignacio Echevarría, Pablo Raphael escribe que, "Como sucedió con la banca y la hostelería, la industria editorial permitió a España recuperar el control de sus viejas colonias, al menos en la lógica de la influencia económicosupranacional. En muy poco tiempo hemos caminado hacia la estandarización del lenguaje. [...] 
En el marco de este rediseño geopolítico, Anagrama se va a insertar, sin duda, como un actor protagónico. Pero si, en contraste con la de Planeta y Alfaguara, su participación económica puede ser considerada acaso secundaria, no se puede sostener lo mismo de su participación simbólica. Anagrama -este es mi argumento- desde 1997 en adelante va a ocupar la posición que Seix Barral había dejado vacante en el sistema y se va a convertir en el productor más prestigioso de literatura latinoamericana mundial. Este desempeño se va a fundar al menos en cuatro factores: 1 . La utilización y actualización del repertorio de estrategias legado por Carlos Barral, 2. Un oportuno y eficiente reacomodo al nuevo diseño geopolítico, 3. Una capitalización sumamente efectiva del excedente simbólico con lo que se va a desmarcar de la competencia que representan los grupos Alfaguara/Santillana/Prisa, Random House/Penguin/Mondadori/Bertelsmann y Planeta y 4. El inesperado éxito internacional de Roberto Bolaño y el consecuente flujo de capital simbólico y económico que va a usufructuar Anagrama para reinvertirlo en posteriores apuestas como Alan Pauls, Martín Kohan, Pedro Juan Gutiérrez, Martín Caparrós y, más recientemente, Guadalupe Nettel o Juan Pablo Villalobos.

La colección “Compactos” está activa desde 1989, como serie de bolsillo, y reúne principalmente reediciones sin que ahora importe si se trata de textos escritos en castellano o publicados en traducción, es decir, que en ella tiene lugar una suerte de síntesis entre "Panorama de narrativas" y "Narrativas hispánicas". En ella -anuncia el sitio web de la editorial- simplemente "confluyen los mejores títulos del catálogo de Anagrama”, lo que en 1989, entre otros, comprendía $A$ pleno sol, de Patricia Highsmith, Factotum, de Charles Bukowski y En el camino, de Jack Kerouac; todavía sin títulos de autores hispanohablantes. En 1990 reaparecen Highsmith y Bukowski junto a William Faulkner, Truman Capote y Roald Dahl y los dos primeros títulos de autores españoles e hispanohablantes en general: El mismo mar de todos los veranos, de Esther Tusquets, y El héroe de las mansardas de Mansard, de Álvaro Pombo. La misma tendencia, con muy escasa presencia de escrituras en castellano, se va a mantener incluso hasta el presente aunque con pequeños irrupciones de escritores latinoamericanos como la que en 1993 representan Juan Rulfo con Pedro Páramo y El llano en llamas y Gabriel

lo que hay es un circuito de circulación literaria en el que España actúa como auténtica metrópoli. Además es un circuito radial que conecta siempre desde España y no crea conexiones internas entre los países latinoamericanos. El escritor que quiere alcanzar visibilidad tiene, entonces, que postularse en un mercado en el cual una de las condiciones tácitas es una lengua relativamente estándar, que no particularice. Hay una renuncia instintiva del escritor latinoamericano a conectar con el habla, y aunque conecte, conecta con un habla estandarizada" (24-25). 
García Márquez con El coronel no tiene quien le escriba. Otros escritores latinoamericanos que van a llegar a poseer títulos en la colección son Augusto Monterroso, Roberto Bolaño, Pedro Juan Gutiérrez, Sergio Pitol, Alan Pauls, Alfredo Bryce Echenique, Laura Restrepo, Ricardo Piglia, Juan Villoro, Alonso Cueto, Andrés Neuman, Alejandro Zambra y Martín Caparrós, con una amplia diferencia a favor de Bolaño y, en segundo lugar, de Pedro Juan Gutiérrez.

Propongo, para cerrar este apartado, que las colecciones centrales que conforman el catálogo de Anagrama -"Panorama de narrativas", "Narrativas hispánicas" y, finalmente, la síntesis "Compactos"9- pueden ser concebidas como una imagen especular de lo que efectivamente es la literatura mundial. También que los procedimientos implicados en la selección, jerarquización y organización de los títulos constituyen los mecanismos concretos que dan lugar al corpus de literatura mundial. La literatura latinoamericana mundial, desde este punto de vista, va a ser un fenómeno relativamente reciente, concebido en Barcelona, por cuenta de un actor privado con sus naturales intereses económicos y su correspondiente horizonte cultural, como parte complementaria y subordinada de un patrimonio literario mayor definido como "hispánico". Algunos escritores, ejemplarmente Bolaño, van a contar con tal aprobación que van a llegar a compartir colección con y ubicarse a la par de William Shakespeare, Vladimir Nabokov, Jack Kerouac o William Faulkner. Otros, la mayoría, jamás van a poder siquiera aspirar a ser parte del corpus de literaturas bajo influjo simbólico de la metrópoli. Sus escrituras van a permanecer inscriptas en los dominios de las literaturas locales. La poesía, por su parte -y voy a retomar el tema-, no solo va a quedar excluida de cualquier posible enlace con el orden de lo mundial sino también, y de manera más elemental, con la cobertura semántica implicada en el término literatura.

9 También la colección "Argumentos" es de suma importancia. En tanto colección inaugurada en 1969 y aún hoy en plena vigencia, resulta central para el proyecto de Herralde. Si no la considero en este estudio, es, ante todo, porque mi atención se concentra en la literatura de ficción, pero también porque es sobre la base de las colecciones de narrativa que la editorial ha labrado su prestigio y popularidad. De acuerdo con el editor, además, “Actualmente, 'Narrativas hispánicas’ es la colección más importante de la editorial” (“Introducción...” 21) con lo que queda acentuada no solo la importancia que posee la narrativa frente a la del ensayo, sino también la de la narrativa identificada como latinoamericana. 